\title{
Leitura e negociação de sentidos: coordenadas para uma prática escolar dialógica
}

\section{Reading and meaning negotiation: guidelines for a dialogic educational practice}

\author{
Viviane de Vargas Geribone* \\ Adriano de Souza**
}

\begin{abstract}
RESUMO: Este artigo aborda o tema da leitura, apresentando e discutindo a relevância de um modelo sociocognitivo de negociação de sentidos. Para tanto, analisamos a questão da leitura no documento Base Nacional Comum Curricular (BNCC), com foco nas habilidades do componente Língua Portuguesa (LP), da seção Ensino Médio (EM). Utilizamos uma abordagem metodológica de cunho interpretativista e desenvolvemos alguns pressupostos teóricos implicados na noção de leitura como negociação de sentidos. Apresentamos duas premissas para negociação de sentidos em práticas de leitura, a saber, confrontação interativa e concertação participante. A análise da BNCC revelou a presença de dois tipos de habilidades, sendo um conjunto mais afeito às práticas horizontais de negociação de sentidos e outro menos alinhado a essa finalidade.
\end{abstract}

PALAVRAS-CHAVE: leitura; negociação de sentidos; modelo sociocognitivo; BNCC.

ABSTRACT: This paper deals with the subject of reading, presenting and discussing the relevance of a sociocognitive pattern of meaning negotiation. To support this discussion, we have analyzed the reading issue in the Base Nacional Comum Curricular (BNCC), focusing on Portuguese Language subject skills in the section about high school. We have used an interpretivist methodological approach and developed some theoretical assumptions implied in the notion of reading as meaning negotiation. We present two premises to meaning negotiation in reading practices: interactive confrontation and participant conciliation. The BNCC analysis revealed the presence of two types of skills: one of them more likely to meaning-negotiation horizontal practices and another one less aligned to that purpose.

KEYWORDS: reading; meaning negotiation; sociocognitive theory; BNCC.

\footnotetext{
* Viviane de Vargas Geribone é mestra em Educação (URI) e doutoranda em Letras - Linguística Aplicada (UFRGS). E-mail: vigeribone@gmail.com, ORCID https://orcid.org/oooo-ooo1-93086015.

** Adriano de Souza é professor da Universidade Federal do Pampa, mestre em Letras - Estudos Literários (UFSM) e doutorando em Letras - Linguística Aplicada (UFRGS). E-mail: d.souzadriano@gmail.com, ORCID https://orcid.org/oooo-0001-9015-465X.
} 


\section{Introdução}

A pesquisa sobre leitura tem delineado, pelo menos, três vias ou perspectivas pelas quais se pode buscar uma aproximação do fenômeno da leitura. De um lado, as teorias cognitivas, interessadas pelos procedimentos mentais conjugados na produção de sentido, tais como inferências, atenção, memória, percepção, entre outros. Há também as teorias da linguagem enunciativo-discursivas, que se propõem a perceber a leitura como processo de produção de sentido em situações de uso e concretude do ato comunicativo. E há, nos estudos de letramento, uma terceira via, interessada em perceber "os processos sócio-históricos e culturais envolvidos na leitura” (KLEIMAN, 2013, p. 9), sinalizando, pelo enfoque antropológico, a complementariedade entre as duas perspectivas acima referidas.

Mencionamos essas três porque talvez sejam as que aparecem com mais frequência no campo da formação de professores(as) de Letras, mas, evidentemente, há outras formas de abordar o objeto em questão. Sendo assim, qualquer que seja a porta de entrada ao tema da leitura, os(as) interessados(as) em pesquisá-lo devem ter presente, assim nos parece, que: (i) há extensa produção acadêmica e vasta literatura nas três abordagens, motivo pelo qual há de se escolher uma para tentar mapear razoavelmente seu estado da arte; e (ii) ainda que, com base em profunda imersão no campo, se consiga fazer um bom levantamento da produção acadêmica, há de se ter em conta que se trata apenas de um enfoque entre, pelo menos, outros dois a serem considerados, justificandose, assim, a necessidade de especificidade e delimitação da pesquisa.

Se é recomendado ao(à) pesquisador(a), sobretudo ao(à) iniciante, que delimite muito bem sua região de atuação teórico-metodológica; por outro lado, a tarefa da pedagogia da leitura é, talvez, ainda mais complexa, já que se espera do(a) professor(a), sobretudo do(a) docente de Educação Básica, que conheça com alguma profundidade o maior número de enfoques possíveis do fenômeno em tela, isso porque - em se tratando de aprendizagem de leitura, fenômeno que transversaliza a vida escolar (e extraescolar) - a natureza desse ofício exige 
redobrada atenção aos múltiplos aspectos do fenômeno, para que possa mobilizar e orientar as constantes tomadas de decisão necessárias e requeridas.

Pensando nisso, este texto se organiza a partir da seguinte preocupação: como orientar e reorientar estratégias, enfoques e tomadas de decisão em ambientes de pedagogia de leitura considerando os múltiplos aspectos desse fenômeno? Para tanto, seguimos os seguintes passos: (i) apresentamos as coordenadas teóricas implicadas na noção de leitura como negociação de sentidos; (ii) apresentamos um modelo sociocognitivo de construção de sentido, que leva em consideração leitor, docente, texto e contexto de sala de aula, elaborado por Ruddell, Unrau e Mccormick (2019); e (iii) como insumo para discutir a noção de leitura como negociação de sentidos, olhamos para a Base Nacional Comum Curricular, Língua Portuguesa, Ensino Médio (BNCC/EM-LP), a fim de saber de que forma um modelo sociocognitivo de construção negociada de sentidos pode dialogar com a noção de leitura da BNCC/EM-LP (MEC, 2018). Ao final do texto, apresentamos algumas asserções de caráter mais reflexivo, com vistas a traçar limites, desafios e potencialidades da discussão proposta. Nossa expectativa é que este texto possa servir como uma espécie de bússola a quem venha a se aventurar no mar do ensino e da aprendizagem de leitura.

\section{A questão da leitura como negociação de sentidos possíveis: o que está pressuposto em termos teóricos?}

Quando falamos em negociação de sentido em práticas de leitura, é necessário pontuar alguns conceitos e noções importantes que nos possibilitam imprimir solidez ao nosso caminho investigativo de modo geral e à perspectiva sociocognitiva em particular, dentro da qual estamos propondo pensar as noções de leitura, linguagem e aprendizagem, e como essas três noções podem se aproximar, em contextos presumidamente de ensino e aprendizagem de línguas, por meio da noção de letramento.

Pensar a leitura na perspectiva que temos desenvolvido aqui equivale a pensar a linguagem a partir da tradição teórica que lhe reconhece uma natureza dialógica. O que significa, nos termos de Volóchinov (2017), compreender - em 
certa medida, desvendar - a inter-relação dinâmica entre o discurso autoral e o discurso reportado presente em todo enunciado. Em outras palavras, estamos propondo que as bases da noção de leitura como atividade de negociação (diálogo entre partes diferentes) já estavam lançadas na teoria da linguagem desenvolvida pelos autores do contexto russo de início do século XX. Vale dizer, portanto, que a procura de Volóchinov (2017) por um método sociológico, pelo qual se pudesse melhor compreender as formas de transmissão do discurso alheio, aponta para o fato de que a atividade de leitura é uma estratégia (não a única, mas talvez a mais importante) de adentrar o mundo psicossocial das formas simbólicas, onde reside toda a sorte de comportamentos, práticas e atividades humanas. É impossível entrar nesse mundo - e nele se colocar em pé - sem levar consigo a própria bagagem e, a partir de seu conteúdo, interferir na dinâmica historicamente organizada pelos seres que aí habitam e habitaram.

Na esteira do que temos desenvolvido, parece válido acrescentar o ponto de vista de James Paul Gee (2019) a esse propósito. Esse autor - discordando da afirmação de que a função da linguagem seja a de apenas transmitir informações - argumenta que há duas funções primordiais para a linguagem humana, a saber: (i) sustentar a ação humana no mundo, incluindo atividades sociais, interações, experiências em geral; e (ii) sustentar a afiliação humana em culturas, grupos sociais e instituições, criando as possibilidades para tal e convencendo outros a terem certas perspectivas sobre determinada experiência (GEE, 2019). Essa noção de experiência permite a Gee (2019) construir um diálogo com os estudos de cognição situada (situated cognition studies) para sustentar a afirmação segundo a qual a construção de sentido está atrelada às experiências vivenciadas por pessoas em ações situadas no mundo material e social ${ }^{1}$. Não se trata, portanto, de pensar o processo cognitivo de construção de sentido enquanto uma representação abstrata da linguagem humana, mas como ato experiencial. Assim, ler, compreender e construir sentido compõem um ato experiencial na medida

\footnotetext{
${ }^{1}$ São evidentes, aqui, os ecos de Vigotski (2008, p. 103), para quem “o aprendizado desperta vários processos internos de desenvolvimento, que são capazes de operar somente quando a criança interage com pessoas em seu ambiente [...]. Uma vez internalizados, esses processos tornam-se parte das aquisições do desenvolvimento independente da criança”.
} 
em que reverberam a continuidade da ação situada motivadora de tal ato experiencial.

Gee (2019) propõe a seguinte analogia: imaginemos a possibilidade de gravar nossas experiências em videoteipes; nesse caso, teríamos um acervo com diversos arquivos de vídeos editados por nós mesmos. Assim, na medida em que nos deparássemos com novas situações, recorreríamos ao nosso acervo no intuito de assimilar as novas experiências a partir do conteúdo já editado e reeditado do nosso acervo. Os vídeos que compõem tal acervo são, para o autor, o que usamos para dar sentido às experiências no mundo e, consequentemente, o que usamos para atribuir sentidos a palavras e frases; todavia, tais vídeos não se apresentam necessariamente como linguagem verbal, mas como representações da existência (sentimentos, atitudes, posições etc.), ou seja, filmes carregados de perspectiva e escala valorativa, com os quais construímos sentidos em eventos situados pela atividade interativa ${ }^{2}$.

Se, por um lado, está claro que os processos cognitivos que envolvem assimilação de novas experiências não se reduzem à analogia dos videoteipes - e isso o próprio autor reconhece 3 -; por outro lado, a metáfora ajuda a compreender quase que didaticamente como imprimimos nossa perspectiva aos processos de leitura e de interações de que participamos (ao passo que ela mesma - a perspectiva - vai se construindo) e, sobretudo, como a aprendizagem se estabelece dentro de práticas efetivamente situadas ou, em outras palavras, dentro de um ato experiencial. Nos termos de Vigotski (2008), diríamos que o ato experiencial é a faísca que aciona os processos internos de desenvolvimento do(a) aprendiz.

Na linha dos estudos de cognição situada, autores como Etienne Wenger e Jean Lave (1991) têm, a partir de estudos antropológicos, trabalhado com a ideia de aprendizagem situada (situated learning), posição segundo a qual a característica central da aprendizagem, vista como atividade situada (dimensão

\footnotetext{
2 Em seu tempo, Paulo Freire (2009, p. 11) já chamava a atenção para o fato de que "a leitura do mundo precede a leitura da palavra, daí que a posterior leitura desta não possa prescindir da continuidade da leitura daquele".

3 "Of course, talking about videotapes in the mind is a metaphor that, like all metaphors, is incorrect if pushed too far": "É claro que falar em videotape na mente é uma metáfora que, como todas as metáforas, é incorreta se for levada longe demais" (GEE, 2019, p. 106, tradução nossa).
} 
integral e inseparável da prática social), reside no processo de participação periférica legitimada que ela (a aprendizagem) cria ${ }^{4}$. Em resumo, para esses autores, a aprendizagem engendra um processo de participação periférica legitimada (LAVE; WENGER, 1991). Mas o que vem a ser esse processo e, sobretudo, que contribuição ele dá para pensarmos as questões relacionadas à negociação de sentido em práticas de leitura?

Esses autores pesquisaram diferentes grupos sociais com vistas a observar a relação entre aprendizes e aprendizagem em práticas situadas dentro do que chamaram de comunidade de prática (community of practice). Seus estudos deram origem à percepção segundo a qual a aprendizagem implica um modo peculiar de engajamento de participantes em determinadas práticas sociais muito mais do que a assimilação passiva de habilidades cognitivas ou a construção de estruturas mentais para sua assimilação. A esse modo peculiar de engajamento e pertencimento a uma comunidade de prática, Lave e Wenger (1991) chamaram participação periférica legitimada, destacando, do ponto de vista analítico, tratar-se de uma espécie de descritor do comprometimento em determinada prática social.

A participação periférica legitimada é uma noção complexa, sobretudo porque não pretende dicotomizar em termos de "periférico"/"central" ou "legítimo"/"ilegítimo" a percepção a respeito de práticas de aprendizagem situada. Grosso modo, trata-se de pensar a aprendizagem como: (i) engajamento, envolvimento, comprometimento, pertencimento, participação no mundo social; (ii) mudança de comportamento social, que pode interferir na construção de identidades e nas formas de participação no mundo social; (iii) participação periférica legitimada e participação plena em comunidades de prática; sendo que não necessariamente e fatalmente a participação periférica tenha que conduzir determinado participante à participação plena, haja vista que a aprendizagem, nesses termos, não implica uma escala valorativa em que o pleno é melhor que o periférico - tampouco implica que haja um único centro dentro do qual estejam

\footnotetext{
4 "Learning viewed as situated activity has as its central defining characteristic a process that we call legitimate peripheral participation": "A aprendizagem vista como atividade situada tem como característica definidora central um processo que chamamos de participação periférica legítima/legitimada" (LAVE; WENGER, 1991, p. 29, tradução nossa).
} 
os mais capacitados ou uma única periferia na qual estejam os(as) recémchegados(as). Ambos, pleno e periférico, são legitimamente participantes, podendo, inclusive, ser estratégico, para cada um deles, manter ou trocar sua participação em diferentes comunidades de prática.

Percebe-se, então, que a noção de participação periférica legitimada e o consequente engajamento e pertencimento dos(as) participantes que a noção implica estão profundamente incorporados na noção de linguagem desenvolvida por Gee (2019). Retomando, para o autor, a linguagem possui duas principais funções: dar sustentação a nossas interações no mundo social e promover nosso alinhamento a determinadas culturas, grupos sociais e instituições, enquanto tratamos de buscar convencer outras pessoas a adotar esta ou aquela perspectiva frente a determinadas experiências e, assim, fortalecer o próprio grupo de que se faz parte. Ora, essas características pontuadas por Gee (2019), que são a razão de ser da linguagem humana, dizem respeito, fundamentalmente, ao engajamento e à mudança de comportamento social que implica toda aprendizagem situada logo, que implica a participação periférica legitimada e a participação plena de que falam Lave e Wenger (1991). É dentro dessa articulação teórica que percebemos o conceito de letramento de modo geral e, em particular, a noção de letramento escolar. Trata-se, portanto, de um fenômeno sócio-histórico e sociocognitivo manifestado em práticas sociais, em que se pode observar diferentes modos de uso da linguagem pautando diferentes comportamentos sociais.

Eis aí o ponto central da discussão. Quando transpomos tais reflexões para ambientes formais escolarizados de aprendizagem e ensino, também podemos falar em aprendizagem situada em comunidades de prática. Da mesma forma que podemos pensar em leitura como participação periférica legitimada e participação plena em comunidades de prática. Daí que passa a ser razoável falar em mediação de leitura e negociação de sentidos em práticas de leitura, constatação esta que nos leva à seguinte indagação: quando elaboramos nossos projetos e práticas de ensino, estamos realmente cientes de todas as variáveis (ou pelo menos daquelas mais significativas) envolvidas nas práticas escolares de leitura e de formação de leitores(as)? 


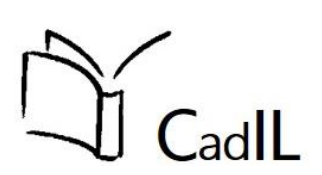

\section{Um modelo sociocognitivo de leitura com vistas a práticas de negociação de sentido entre agentes do campo escolar/instrucional}

Para tratar da questão levantada no fim da seção anterior, trazemos à baila um modelo5 de construção e negociação de sentidos em práticas de leitura numa perspectiva sociocognitiva, que considera as seguintes instâncias: leitor, docente, texto e contexto de sala de aula. Esse modelo foi elaborado pelos pesquisadores Robert Ruddell, Norman Unrau e Sandra McCornick (2019). Na versão que apresentamos abaixo, o texto não verbal é idêntico ao original, e o texto verbal foi, por nós, livremente traduzido.

\footnotetext{
5 Estamos pensando em modelo conforme Unrau, Alvermann e Sailors (2019), para quem um modelo serve como metáfora para explicar e representar determinada teoria. Nesses termos, um modelo é estático e representa um instantâneo de um processo dinâmico (teoria).
} 
Figura 1 - Modelo sociocognitivo de construção de sentido: leitor(a), docente, texto e contexto de sala de aula.

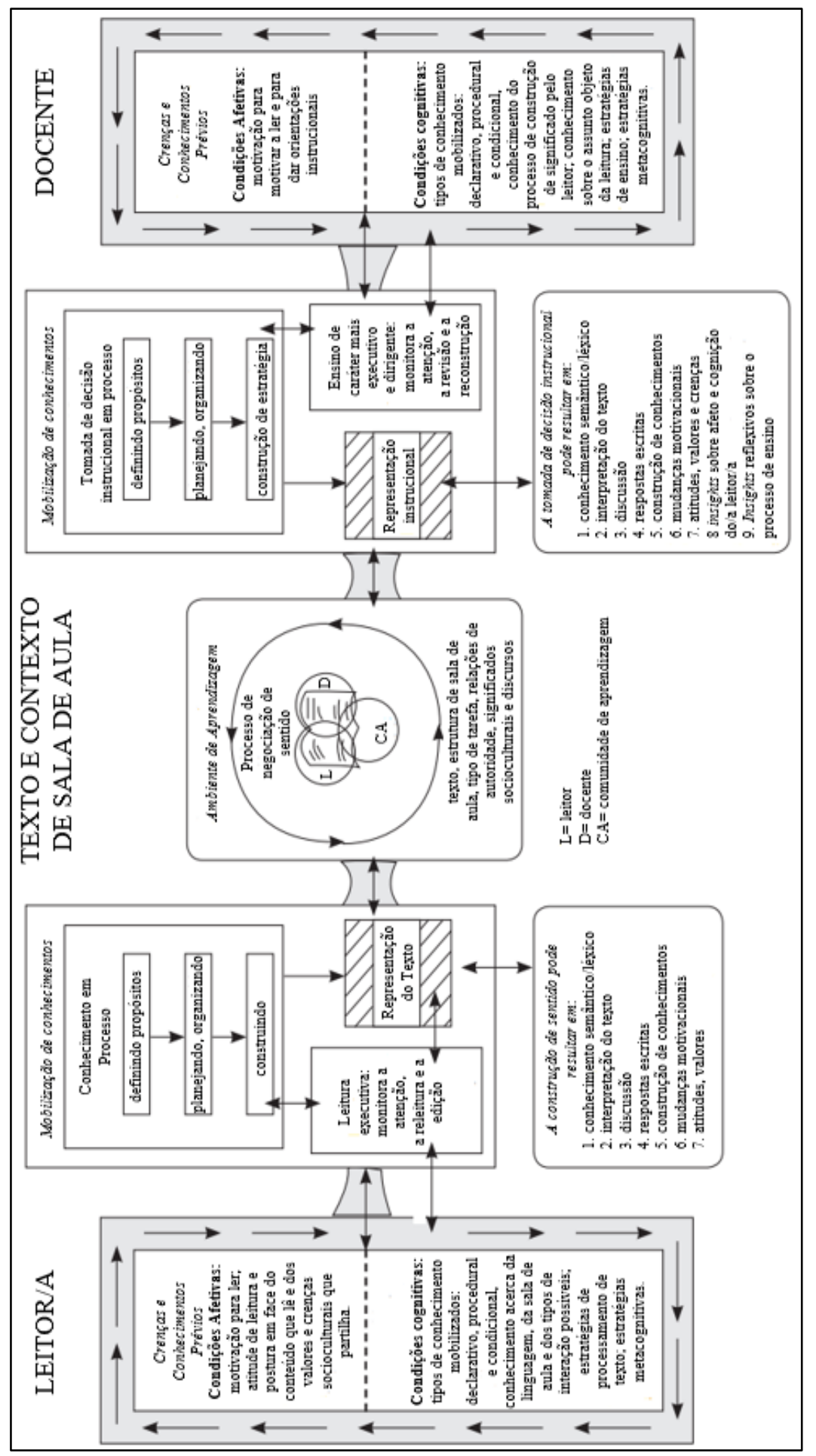

Fonte: Adaptado de Ruddell, Unrau e Mccormick (2019, p. 205). 
O ambiente de aprendizagem é o ponto central do modelo: para ele convergem as instâncias agentivas docente e leitor(a). Propomos explorar uma leitura do modelo partindo do centro para as extremidades. Nesse caso, somos convidados a entrever o que cada agente do ato experiencial de leitura leva para a mesa de negociações que, em boa medida, constitui um ambiente de aprendizagem. Do lado esquerdo, o(a) leitor(a), dotado de condições afetivas e cognitivas específicas que configuram seus conhecimentos e crenças prévias a partir dos quais deverá elaborar uma primeira representação do texto objeto motivador da leitura. Do outro lado, o(a) docente e suas crenças, valores e conhecimentos, organizados por condições e motivações afetivas e cognitivas específicas, as quais lhe servirão de suporte para a construção de estratégias de leitura, abordagens e tomadas de decisão no processo instrucional de mediação de leitura.

Entre eles, um texto a ser pautado e a presença de uma comunidade de aprendizagem de sala de aula. Imaginemos uma sala de aula com vinte jovens, e essa mesa de negociações já se tornou uma plenária de uma grande assembleia. Daí que passa a ser estratégico pensar na configuração do ambiente de aprendizagem como uma comunidade de prática de leitores(as), pela qual circulam participantes plenos e participantes periféricos legitimados. Para tanto, recomenda-se que o tema, o projeto, a estratégia, a abordagem, enfim, aquilo que irá motivar a leitura de determinado texto seja gerado explicitamente na interação entre os agentes do contexto de sala de aula. Em outras palavras, estamos argumentando que, para haver negociação de sentido entre membros de uma comunidade de prática de leitura, é salutar que os(as) participantes estejam, segundo nos parece, a par de duas premissas, a saber:

1) confrontação interativa, em que os(as) participantes estão orientados por algum interesse maior - aquilo por que se vale a pena negociar, considerando a sustentação da ação dos(as) participantes no mundo social e sua vinculação a grupos identitários, comunidades de prática outras, coletivos, instituições etc. -, para além da simples tarefa escolar da leitura ou da narrativa quase mítica que confere à atividade leitora poderes emancipatórios; 
2) concertação $o^{6}$ participante, em que os(as) interactantes estão cientes de que os significados possíveis de determinada prática de leitura não estão tão-somente no texto ou no leitor, mas resultam da interação textoleitor-docente-demais participantes da comunidade de aprendizagem da sala de aula.

O modelo de Ruddell, Unrau e Mccormick (2019) - justamente porque coloca na centralidade do processo de leitura a negociação de sentido, considerando a complexidade do ato de ler e a pluralidade de fatores, de agentes e de interesses envolvidos e mobilizados - parece bastante producente para ampliar a noção tradicional que reduz a atividade leitora a uma habilidade individual e meramente cognitiva. Há limitações, evidentemente, sobretudo porque um modelo é, em si, uma imponderável tentativa de congelar algo que está em plena atividade dinâmica. Além disso, o modelo silencia sobre, por exemplo, as diferentes relações de poder que estão envolvidas em toda prática de negociação. Entretanto, relevando tais aspectos, destacamos sua profícua capacidade de mapear os múltiplos fatores que interferem na dinâmica de negociação de sentido de práticas de pedagogia de leitura, o que o torna operacional quando está em jogo, por exemplo, o planejamento de projetos didáticos de ensino. Em outras palavras, entendemos que esse modelo sociocognitivo de negociação de leitura pode ser um aliado fundamental para orientar e reorientar as estratégias, enfoques e tomadas de decisão em ambientes de pedagogia de leitura, contribuindo, inclusive, para o mapeamento de alguns dos múltiplos aspectos desse fenômeno.

Recuperando nossa trajetória até aqui: tratamos, num primeiro momento, da discussão de fundo teórico acerca dos pressupostos e fundamentos que sustentam a noção de leitura como negociação de sentido. Tal noção, como vimos, está embebida tanto de teorias cognitivas sobre leitura como da influência de teorias sociointeracionistas da linguagem, da psicologia e da aprendizagem,

\footnotetext{
${ }^{6}$ Essa palavra não está dicionarizada nas versões do Aurélio e do Houaiss que consultamos. Tratase, no nosso entendimento, de um conceito empregado com maior frequência no campo da política, designando uma ampla articulação no sentido da construção de um consenso, na elaboração de uma negociação, na instauração de um pacto social.
} 
motivo pelo qual passamos a lidar com um modelo sociocognitivo de negociação de leitura, no qual estão implicados leitor, texto, docente e contexto. Discutindo brevemente esse modelo, apresentamos duas premissas a serem pactuadas entre os(as) diferentes agentes do ato de leitura para que seja, nessa prática, assegurada a negociação de sentidos, chamamos essas premissas de confrontação interativa e concertação participante. Com vistas a encaminhar a presente discussão, passamos a um segundo momento deste texto em que nos colocamos a seguinte questão: uma vez que o(a) docente esteja a par de toda complexidade envolvida na construção de uma pedagogia de leitura alinhada a um modelo sociocognitivo de negociação de sentidos, a Base Nacional Comum Curricular (MEC, 2018) ampara tal abordagem?

\section{Competências, habilidades, práticas de linguagem: algumas escolhas da BNCC}

Diante do caráter recente de publicação da BNCC (MEC, 2018), não nos parece desnecessário apresentar, em linhas gerais, um pouco da sua organização discursiva. Optamos por olhar o capítulo destinado ao Ensino Médio (EM)7, mais especificamente nosso enfoque se deteve nas práticas de leitura - que juntamente com produção textual, oralidade, análise linguística/semiótica, compõem um eixo mobilizador de diferentes habilidades - do componente Língua Portuguesa (LP), da área de Linguagens e suas Tecnologias. É impossível fazer esse recorte sem realizar a ressalva de que o documento está construído como uma totalidade quase sistêmica, em que cada parte se liga a outra organicamente. Assim, o capítulo destinado ao EM está conectado às Competências Gerais da Educação Básica; as Competências Específicas das áreas de Linguagens, Matemática, Ciências da Natureza e Ciências Humanas e Sociais do EM estão, evidentemente, em diálogo com as Competências Específicas das áreas correspondentes ao

\footnotetext{
7 Segundo o documento, "a BNCC do Ensino Médio não se constitui no currículo dessa etapa, mas define as aprendizagens essenciais a ser garantidas [sic] a todos os estudantes e orienta a (re)elaboração de currículos e propostas pedagógicas, seja no que diz respeito ao âmbito específico da $\mathrm{BNCC}$, seja no tocante à organização e à proposição de itinerários formativos [...]" (MEC, 2018, p. 471).
} 
Ensino Fundamental (EF). Da mesma forma, quando lançamos um olhar comparativo entre EM e EF para o componente Língua Portuguesa e para seus eixos de integração há, obviamente, uma relação de continuidade entre ambos, de tal maneira que o recorte analítico que estamos propondo aqui deve se sustentar na medida em que consideramos essa relação orgânica entre as partes, mesmo que a ela não façamos maiores conjecturas, dado o espaço reduzido de que dispomos neste texto.

Para os fins aqui propostos, é suficiente compreender que o documento se organiza a partir da lógica do saber e do saber fazer. Essa lógica se desenvolve em termos de competências e habilidades, como já sinalizamos. Sendo assim, conforme a BNCC (MEC, 2018, p. 8), o termo competência corresponde à "mobilização de conhecimentos [...], habilidades [...], atitudes e valores para resolver demandas complexas da vida cotidiana, do pleno exercício da cidadania e do mundo do trabalho", algo que se aproxima, se quisermos, do saber para saber fazer. Quanto às habilidades, ainda conforme o documento, "expressam as aprendizagens essenciais que devem ser asseguradas aos alunos nos diferentes contextos escolares" (MEC, 2018, p. 29). Para tanto, elas são descritas de acordo com uma determinada estrutura enunciativa, a saber: verbo (que indica um processo cognitivo) + complemento (que indica um objeto do conhecimento) + modificadores (que indicam um contexto e/ou um especificador). Ou seja, uma habilidade é um saber, que envolve um processo cognitivo, um objeto e um contexto desse saber. Como exemplo, temos a habilidade EM13LP17 apresentada da seguinte maneira:

\footnotetext{
Elaborar roteiros para a produção de vídeos variados (vlog, videoclipe, videominuto, documentário etc.), apresentações teatrais, narrativas multimídia e transmídia, podcasts, playlists comentadas etc., para ampliar as possibilidades de produção de sentidos e engajar-se em práticas autorais e coletivas. (MEC, 2018, p. 509)
}

Tal habilidade refere-se a um processo cognitivo (elaborar); a um objeto de conhecimento (roteiro; que pode ser voltado para a produção de vídeos, de apresentações teatrais, de narrativas multimídias etc.) e a um contexto ou modificador que estabelece maior especificação da aprendizagem esperada (no caso, elaborar o roteiro para ampliar a produção de sentido e para favorecer o 
engajamento em práticas autorais e coletivas). Junto a isso, é interessante observar que, na seção destinada ao EF, o documento acrescenta que "as habilidades não descrevem ações ou condutas esperadas do professor, nem induzem à opção por abordagens ou metodologias” (MEC, 2018, p. 30). Ou seja, trata-se, em tese, de respeitar a autonomia didático-pedagógica do(a) professor(a).

Não obstante, a relação entre competência e habilidades, entre saber e saber fazer, envolve processos sociais e cognitivos. Daí a possibilidade de ler a BNCC como um documento que orienta a construção de currículos de Educação Básica numa perspectiva teórica de matriz sociocognitiva, ou seja, dentro do paradigma sociocognitivista. Essa perspectiva de trabalho tende a favorecer abordagens que percebem a linguagem humana como integrante inseparável da dinâmica social de trocas interacionais. Significa dizer, então, que uma pedagogia de leitura que se pretenda alinhada a uma perspectiva sociocognitiva de leitura como negociação de sentidos encontra respaldo na BNCC, cabendo, por fim, saber em que medida as habilidades de cada etapa escolar são mais ou menos propícias a tal abordagem.

\section{Leitura e negociação de sentido em habilidades do componente LP na BNCC Ensino Médio: alinhamentos e desalinhamentos}

Nesta seção do trabalho, buscamos analisar as habilidades da BNCC/EMLP (MEC, 2018) tendo em vista a possibilidade de construção de uma pedagogia de leitura alinhada a uma abordagem sociocognitiva de negociação de sentidos, nos termos do modelo que apresentamos anteriormente e considerando as escolhas teóricas do documento conforme já apresentado.

Como a seção da BNCC destinada ao EM não divide as habilidades por práticas de linguagem, como acontece no EF, em que há habilidades próprias para leitura, outras para análise linguística/semiótica, outras para oralidade e outras para produção escrita, em nossa análise de cunho interpretativista (MOITA LOPES, 1994), selecionamos as habilidades cujas estruturas 
enunciativas sugerem ações e/ou processos reconhecidamente realizados através do ato de ler (como analisar, selecionar, compartilhar sentidos etc.).

De posse disso, retomamos as duas premissas apresentadas anteriormente - a saber, confrontação interativa e concertação participante -, a partir das quais questionamos as habilidades de língua portuguesa do EM. Procuramos saber em que medida essas habilidades de leitura de língua portuguesa no EM, da maneira como estão enunciadas, favorecem práticas de negociação de sentidos ou, pelo menos, indicam haver espaço para essa abordagem. Ou seja, considerando que as habilidades se estruturam como processo cognitivo + objeto de saber + contexto ou modificador/complemento, procuramos saber se elas são coerentes com as premissas confrontação interativa e concertação participante, que são, como vimos, princípios gerais a serem pactuados em práticas de leitura para que se tenha minimamente assegurado um trabalho de negociação de sentidos em pedagogia de leitura.

Observamos, assim, a existência de dois grupos de habilidades (identificadas, no quadro abaixo, como tipo 1 e tipo 2). Encontramos, num primeiro momento da análise, tanto habilidades mais alinhadas a um trabalho de construção e negociação de sentido em práticas de leitura, como habilidades menos alinhadas a um trabalho nesses termos (estas em menor número). No quadro a seguir, apresentamos um exemplo prototípico mais representativo de cada um dos grupos, seguido de comentários analíticos.

Quadro 1 - Habilidades conforme maior ou menor alinhamento a um trabalho de construção e negociação de sentidos em práticas de leitura

\begin{tabular}{|l|}
\hline Tipo 1 \\
\hline Exemplo: (EM13LPO6) - Analisar efeitos de sentido decorrentes de usos \\
expressivos da linguagem, da escolha de determinadas palavras ou \\
expressões e da ordenação, combinação e contraposição de palavras, dentre \\
outros, para ampliar as possibilidades de construção de sentidos e de uso \\
crítico da língua (MEC, 2018, p. 207). [TC $]^{8}$
\end{tabular}

\footnotetext{
8 Legenda para os campos de atuação social de onde foram retiras cada habilidade: [TC] - todos os campos de atuação; [JM] - campo jornalístico-midiático; [EP] - campo das práticas de estudo e pesquisa; [VPU] - campo da vida pública; [VPE] - campo da vida pessoal; e [AL] - campo artístico-literário.
} 
Comentário: O processo cognitivo em questão (analisar) e o objeto de conhecimento a ser analisado (efeitos de sentido para fins de ampliação das possibilidades de construção de sentidos e uso crítico da língua) deixam espaço para planejamentos didáticos que favoreçam a mobilização de interesses diversos que possam interpelar os interactantes para a negociação de sentidos (confrontação interativa). Também há espaço para supor que a interação entre as partes deve conduzir a construção de significados possíveis (concertação participante). As habilidades desse tipo estão em maioria no EM, especialmente nos campos VPU, TC, AL, JM, e apresentam um maior alinhamento com os pressupostos que sustentam uma abordagem de leitura como construção e negociação de sentido.

\section{Tipo 2}

Exemplo: (EM13LP5O) - Analisar relações intertextuais e interdiscursivas entre obras de diferentes autores e gêneros literários de um mesmo momento histórico e de momentos históricos diversos, explorando os modos como a literatura e as artes em geral se constituem, dialogam e se retroalimentam (MEC, 2018, p. 525). [AL]

Comentário: Em habilidades desse tipo, o desdobramento de seus modificadores tende a isolar disciplinarmente o processo cognitivo e o objeto de conhecimento de seu contexto mais amplo interdisciplinar. Por conta disso, o objeto de saber (nesse caso, intertextualidade e interdiscursividade de obras literárias) tende a ser abordado no limite do recorte enunciado pela habilidade; se esta percepção é válida, o espaço para mobilizar uma confrontação interativa torna-se reduzido. No que se refere à concertação participante, a habilidade parece reservar ao texto (nesse caso, o literário) o foco único da produção de sentido.

Fonte: Elaborado pelos autores.

Pensar a leitura como negociação de sentidos é uma maneira de assinalar o entendimento de que, dentre outras concepções, leitura é uma prática social, mediante a qual pessoas se relacionam dentro de situações comunicativas específicas e propósitos comunicativos minimamente partilhados. Por isso mesmo é que faz sentido pensar - e o esquema da Figura 1 contribui para isso que há uma complexidade de relações envolvendo leitor(a), texto e contexto de leitura. Por outro lado, por sua aparente harmonia visual, a Figura 1 sugere um equilíbrio tácito entre os diferentes agentes do processo de negociação de sentidos, daí que se torna necessário pontuar que esses diferentes agentes do ato de negociação nem sempre estão em pé de igualdade. Para ficar apenas com o contexto escolar, há vezes em que o texto tem um peso diferente na negociação; é 
o que acontece, por exemplo, com textos do cânone literário, aos quais se soma um legado de interpretações e leituras públicas já legitimadas pela tradição letrada. Nesses casos, os sentidos possíveis do texto parecem menos negociáveis, porque, de certa forma, se apresentam como que cristalizados por certa tradição hermenêutica.

Questões como essa nos levam a pensar que talvez os dois tipos de habilidades identificados no Quadro 1 estejam revelando, em verdade, dois tipos de compreensão da atividade de negociação de sentido - sendo um primeiro tipo em que a negociação de sentidos é tanto mais horizontal quanto possível, e um segundo tipo em que a habilidade aponta para certa verticalização na negociação de sentidos.

Ao afirmar de outro modo, num segundo momento da análise, percebemos, então, que tanto a presença de habilidades do tipo 1, que parecem mais alinhadas com a noção de leitura enquanto negociação de sentidos, como a de habilidades do tipo 2, mais centradas no texto e seus diálogos com a tradição e com outros textos e seus processos, pode estar indicando a demarcação de alguns limites a serem observados nas práticas de negociação de sentidos. $O$ recado desse expediente pode ser o de que há momentos em que se deve negociar mais horizontalmente a construção de efeitos de sentido advindos de diferentes leituras de um mesmo texto (tipo 1); e há momentos em que se deve privilegiar o conhecimento do legado já constituído (e sua manutenção), juntamente com o conhecimento dos processos linguísticos, textuais e discursivos pelos quais um texto se estabelece enquanto tal (tipo 2) - do que arriscamos concluir que leitura na BNCC é um saber escolar em torno do qual outros saberes se associam e é uma prática social pela qual determinadas pessoas fazem coisas específicas, mediadas pelo conhecimento partilhado de uma tecnologia gráfica.

Assim, a construção de uma pedagogia de leitura alinhada a uma abordagem sociocognitiva de negociação de sentidos nos parece em consonância com o aparato regulador do documento, tendo em vista que suas habilidades indicam, em maior ou menor medida, haver espaço para essa prática de negociação, nos termos do que estamos chamando aqui confrontação interativa e concertação participante. 


\section{Algumas (in)conclusões sobre a análise e seus possíveis desdobramentos em práticas de construção e negociação de sentido em leitura}

Com base no que temos apontado até aqui, percebemos que a própria noção de leitura com a qual a BNCC (MEC, 2018) se propõe a trabalhar - noção esta que, coerentemente com os pressupostos teóricos sociocognitivos, concebe a leitura como trabalho coletivo de interação e como um saber comprometido com um saber fazer - parece mais robusta quando mirada de uma perspectiva como a do modelo sociocognitivo de construção negociada de leitura.

O modelo pode ser visto também como um instrumento de verificação empírica, e não apenas um modelo sociocognitivo de construção negociada de sentidos. Sendo assim, torna-se viável, de um lado, considerar a complexidade envolvida no processo de leitura, mapeando algumas variáveis importantes que interferem na construção e negociação de sentidos e, de outro lado, adotar, a partir da contribuição de Ruddell, Unrau e Mccormick (2019), um ponto de vista alternativo ao que considera a leitura como um esforço estático e o texto como único portador de sentidos.

A questão que propomos (a saber, em que medida a BNCC ampara uma pedagogia de leitura alinhada a um modelo sociocognitivo de negociação de sentido?) passa a ser melhor respondida na medida em que as práticas de leitura, elaboradas a partir da BNCC/EM-LP (MEC, 2018), consigam assegurar e promover, entre seus agentes, a confrontação interativa e a concertação participante, premissas que defendemos aqui como indicadores viáveis da negociação de sentido em atividades de leitura. Chegamos a essas premissas, como o(a) leitor(a) deve ter acompanhado, articulando concepções de linguagem e de leitura com uma concepção de aprendizagem. Essa articulação foi possível porque nos pareceu coerente com o que, em linhas gerais, a BNCC encaminha para a área de Linguagens, especialmente o seu desenho curricular, que permite a observação e a participação de práticas de linguagens organizadas em campos de atuação pré-determinados. 
Confrontação interativa e concertação participante são premissas que elaboramos para sustentar o raciocínio segundo o qual as práticas de leitura são atividades que envolvem necessariamente construção e negociação de sentidos, ainda que o processo de negociação de sentido possa ser ignorado por certa pedagogia da leitura e possa até ser negado por certa didática. As considerações que aqui levantamos sobre a constituição de dois grupos de habilidades na BNCCEM/LP (MEC, 2018), sendo um grupo mais afeito ao trabalho de leitura como prática horizontal de negociação de sentidos e outro menos alinhado a tais pressupostos, não significa necessariamente uma incoerência do documento, uma vez que todas as habilidades, em tese, existem a propósito de competências gerais e específicas.

Considerando a maneira como a BNCC (MEC, 2018) organiza competências e habilidades, nos pareceu razoável que a articulação teórica proposta, bem como o instrumento de verificação empírica, sugerido como alternativa viável à construção de práticas de leitura, obtivessem, no paradigma sociocognitivista, seu principal ponto de apoio. Nesse sentido, a BNCC parece se interessar pelos pressupostos teóricos que orientam a leitura como prática interacional, de índole sociocognitiva e situada sócio-historicamente. Deve-se considerar, no entanto, que o documento apenas estabelece aprendizagens a serem garantidas - o modo como tais aprendizagens serão oferecidas, evidentemente, é prerrogativa das instituições de ensino e facultado aos(às) profissionais da educação.

Considerando habilidade, conforme a BNCC (MEC, 2018), como balizador de aprendizagens essenciais, é razoável que o texto das habilidades do documento tenha esse comportamento variável em relação à maior ou menor abertura a práticas de negociação de sentido. Isso significa, possivelmente, uma tentativa de diálogo com profissionais de diferentes perspectivas teóricas, especialmente professores(as) em atividade escolar, com formação e trajetória diversas. Uma análise mais acurada poderá quantificar os dois grupos de habilidades, considerando a Educação Básica como um todo - e não apenas o EM - e assim encaminhar considerações mais conclusivas sobre a questão da presença de uma orientação que favoreça (ou não) as práticas de leitura como construção e negociação de sentido, de uma forma mais ou menos horizontal. 
Por fim, entendemos que trabalhar com concepção de leitura e, em especial, com essa noção que a compreende enquanto prática interativa de negociação de sentido é de extrema relevância para compreender fenômenos sociais e políticos contemporâneos, daí nossa escolha por ver essa questão na BNCC (MEC, 2018). O Brasil vive um momento em que se vê emergir novamente a promoção de falsas polêmicas como, por exemplo, uma suposta prática de doutrinação ideológica nas escolas, encetada, supostamente, por forças políticas progressistas à esquerda do espectro ideológico. A doutrinação só ocorre quando se nega a possibilidade de negociação de construção de sentidos em práticas leitoras, num movimento diametralmente oposto ao que desenvolvemos neste trabalho, a partir do modelo de Ruddell, Unrau e Mccormick (2019). Práticas de doutrinação, com efeito, foram institucionalizadas durante a Ditadura Militar no Brasil, através de disciplinas como Educação Moral e Cívica e Organização Social e Política do Brasil, que aparelharam as instituições de ensino, enquanto estudantes e professores(as) eram perseguidos(as), presos(as), exilados(as), torturados(as) e assassinados(as) pelas forças de repressão do regime.

As diretrizes educacionais presentes na Constituição Cidadã de 1988 (BRASIL, 1988); na Lei de Diretrizes e Bases da Educação de 1996 (BRASIL, 1996; nos Parâmetros Curriculares Nacionais de 1998 (MEC, 1998); e, mais recentemente, na BNCC (MEC, 2018) representam um esforço das forças democráticas da sociedade brasileira no sentido da organização e repactuação das bases de funcionamento do Estado de direito. Nesse esforço, o campo aplicado à educação dos Estudos da Linguagem tem prestado relevantes contribuições. Alinham-se a elas os avanços da área de ensino de línguas e educação linguística, de onde, assim entendemos, a questão da leitura como prática de construção e negociação de sentidos merece um lugar de destaque, inclusive como uma estratégia de que educadores(as) democráticos(as) podem lançar mão contra a ascensão de posturas autoritárias e antidemocráticas. Dessa luta jamais correremos. 


\section{Referências}

BRASIL. Constituição da República Federativa do Brasil de 1988. Brasília: Presidência da República, 1988. Disponível em: http://www.planalto.gov.br/ ccivil_03/constituicao/constituicao.htm. Acesso em: 13 jul. 2020.

BRASIL. Lei $n^{\circ}$ 9394, 20 de dezembro de 1996. Brasília: Presidência da República, 1996. Disponível em: http://www.planalto.gov.br/ccivil_o3/leis/ l9394.htm. Acesso em: 13 jul. 2020.

FREIRE, Paulo. A importância do ato de ler: em três artigos que se complementam. São Paulo: Cortez, 2009.

GEE, James. Paul. Reading as situated language: A sociocognitive perspective. In: ALVERMANN, Donnaet al. (eds.) Theoretical models and processes of literacy. 7. ed. New York: Routledge, 2019. p. 105-117.

KLEIMAN, Angela. Texto e leitor: aspectos cognitivos da leitura. Campinas: Pontes, 2013.

LAVE, Jean; WENGER, Etienne. Situated learning: legitimate peripheral participation. New York: Cambridge, 1991.

LAVE, Jean. Aprendizagem como/na prática. Horizontes Antropológicos, Porto Alegre, n. 44, p. 37- 47; jul./dez. 2015.

MINISTÉRIO DA EDUCAÇÃO (MEC). Base Nacional Comum Curricular. Brasília: Secretaria de Educação Básica, 2018. Disponível em: http://basenacionalcomum.mec.gov.br/images/BNCC_EI_EF_110518_versaofi nal_site.pdf. Acesso em: 13 jul. 2020.

MINISTÉRIO DA EDUCAÇÃO (MEC). Parâmetros Curriculares Nacionais $3^{\circ}$ e $4^{o}$ Ciclos do Ensino Fundamental. Língua Portuguesa. Brasília: Secretaria de Educação Básica, 2018, 1998.

MOITA LOPES, Luiz Paulo. Pesquisa Interpretativista em Linguística Aplicada: a linguagem como condição e solução. DELTA, v. 10, n. 2, p. 329-338, 1994.

RUDDELL, Robert; UNRAU, Norman; McCORMICK, Sandra. A sociocognitive model of meaning-construction: the reader, the teacher, the text and the classroom context. In: ALVERMANN, Donna et al. (eds.) Theoretical models and processes of literacy. 7. ed. New York: Routledge, 2019. p. 204-232.

UNRAU, Norman; ALVERMANN, Donna; SAILORS, Misty. Literacies and their investigation through theories and models. In: ALVERMANN, Donna et al. (eds.) Theoretical models and processes of literacy. 7. ed. New York: Routledge, 2019. p. 3-34. 
VIGOTSKI, Lev Semenovich. A formação social da mente. 7. ed. São Paulo: Martins Fontes, 2008.

VOLÓCHINOV, Valentin. Marxismo e Fìlosofia da Linguagem: problemas fundamentais do método sociológico na ciência da linguagem. São Paulo: Editora 34, 2017.

Artigo recebido em 15 de maio de 2020 e aceito em 6 de julho de 2020. 